
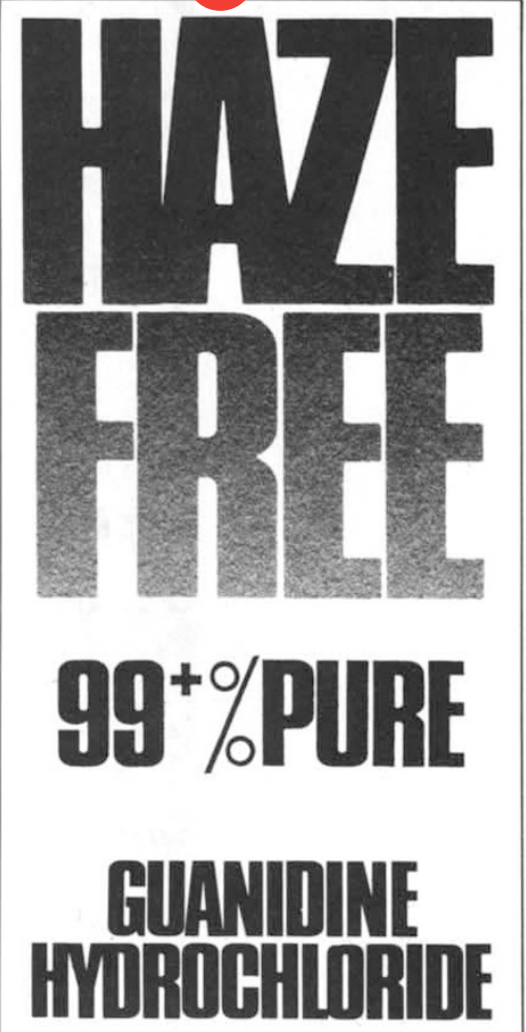

\section{Ultra-High Purity \\ (Biotech Grade)}

Clear and colorless in a $6 \mathrm{M}$ solution.

OD $260 \mathrm{~nm}$ is less than 0.03 .

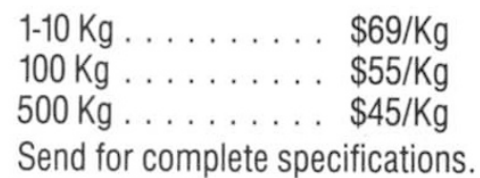

Free catalog of enzymes, substrates and other biotechnology chemicals.

To Order Contact:

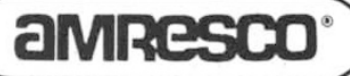

American Research Products Company P.O. Box 21009 - South Euclid, Ohio 44121

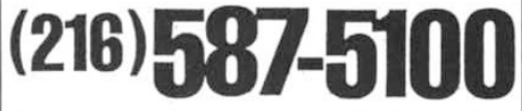

Write in No. 197 on Reader Service Card chemical currently manufactured by fermentation. Reduced enzyme donates its reducing equivalents to an electron carrier, dipyridinum bromide hydrobromide, which is then oxidized at the anode. Electrons are thus set flowing through the external circuit to the cathode, where protons are reduced to hydrogen gas.

Laane and coworkers Koen Dekker and Cees Veeger have also used cellulose for fuel in the anode compartment. Cellulases and $\beta$-galactosidase working together convert cellulose steadily and stoichiometrically to glu- cose-and then, via the action of $\mathrm{D}$ glucose oxidase, to gluconic acid.

Similarly, the inclusion of baker's yeast invertase allowed them to exploit sucrose as fuel. When this reaction was complete, the anode compartment contained fructose and gluconic acid, which could then be separated easily by chromatography. The Wageningen researchers believe that their biochemical cell-using $\alpha$ amylase and an amyloglucosidasewill also function on starch as the fuel.

-Bernard Dixon

\title{
IMPROVING MORELS VIA GENETIC ENGINEERING
}

MUNICH - The possible genetic engineering of morels was a topic of interest at September's biotechnology conference here. Because fruiting bodies of these ascomycetes had not been produced in the laboratory until very recently, they have never been manufactured commercially or subjected to any kind of breeding. After the discovery last year by K. Esser and his colleagues of extrachromosomal genetic elements in fungi (Current $\mathrm{Ge}$ netics 7:29, 1983), F. Meinhart of the Ruhr-Universität Bochum, F.R.G., decided to search for similar DNA fragments in edible mushrooms.

One species of morel, Morchella esculeuta, yielded no such elements. But Meinhart has now found linear extrachromosomal DNA in 8 out of 13 different strains of Morchella conica. Restriction analysis and electron microscopy of the two plasmids discovered in one strain have revealed that their sizes are six and eight kilobase pairs. The $6 \mathrm{kbp}$ element carries inverted repeats of about $0.7 \mathrm{kbp}$ at both ends. As the plasmids appear to be autoreplicative, Meihnhart says, they might represent a valuable tool for the genetic manipulation of these economically important fungi.

Also working at the Ruhr-Universität Bochum, Paul Tudynski and Andrea Duvell described their research on the ergot fungus Claviceps purpurea. Strain improvement has been possible in the past via sexual recombination, but it has been slow and laborious. Tudzymski and Duvell have now found that wild strains of $C$. purpurea contain mitochondrial DNA species which may well serve as a basis for a molecular cloning system. One strain yielded elements of $6.6,5.3$, 10.0 , and $1.1 \mathrm{kbp}$. The first two have several similarities to mitochondrial plasmids described in higher plants (especially Zea maize). They are linear and seem to have short inverted sequences at each end.

-Bernard Dixon

\section{MONITORING FERMENTATION BY HEAT}

MUNICH-Prospects for monitoring biomass production by measuring the heat generated during microbial growth were outlined at the biotech meeting here by Urs von Stockar from the Institute de Génie Chimique, EPFL-Ecublens, (Lausanne, Switzerland), and Ian Marison from the University of Sheffield in England. Previous research had suggested that heat evolution might be correlated with both biomass production and oxygen uptake, but that the ratio of heat to biomass varied considerably according to growth conditions. The possibility of such correlations had stimulated interest in calorimetry as a potential method of regulation. But macrocalorimetric in situ measuring techniques developed so far re- quired a heat balance over the fermentor vessel, which therefore had to be insulated strictly adiabatically. Such methods had not been capable of high sensitivity or of detecting rapidly changing generation rates.

For their studies, von Stockar and Marison have adapted a heat-flux calorimeter (Model BSC81) developed recently by Ciba-Geigy for investigating the thermodynamics of chemical systems. Modified as a stirred tank reactor in which fermentation proceeds under constant temperature, and with sampling and other conventional facilities, the device lets researchers measure rates of heat generation, oxygen consumption, and $\mathrm{CO}_{2}$ evolution continuously.

-Bernard Dixon 